\title{
Mating patterns in an inbred Arctic carnivore
}

\author{
Erika Godoy $^{1} \cdot$ Karin Norén $^{1}\left[\right.$ D Anders Angerbjörn ${ }^{1}$
}

Received: 14 July 2017 / Revised: 8 January 2018 / Accepted: 14 January 2018 / Published online: 29 January 2018

(c) The Author(s) 2018. This article is an open access publication

\begin{abstract}
Mating patterns are highly context-dependent and the outcome of selection pressures formed by ecological factors, inbreeding levels and access to available partners. In small and inbred populations, matings are limited by high kin encounter rates and access to mates. In this paper, we use background pedigree data to investigate mating patterns and inbreeding avoidance in an isolated and critically endangered Arctic fox (Vulpes lagopus) population. Empirical data showed avoidance of matings within natal family. Based on 35 documented matings, we only recorded two full-sibling matings and these occurred between individuals from different natal families. Matings between second-order relatives, however, occurred to the same extent as between unrelated individuals. To test how this influenced the population development of inbreeding $(f)$, we simulated scenarios of random mating, exclusion of natal family and exclusion of individuals in already existing pair bonds. The observed development of inbreeding did not correspond the expected scenario of random mating (linear regression, $r^{2}=0.354, P=0.20$ ), but showed a comparable outcome as the simulated development of discriminating natal family (linear regression, $r^{2}=0.980, P<0.001$ ). We conclude that behavioural, pre-copulatory inbreeding avoidance strategies occur in this population and that exclusion of mating with natal family causes a slower increase in inbreeding levels compared to random mating. This study demonstrates how long-term monitoring, pedigree construction and simulations can generate information valuable for an in-depth understanding of both conservation genetics and behavioural ecology in threatened populations.
\end{abstract}

Keywords Cost $\cdot$ Discrimination $\cdot$ Fitness $\cdot$ Inbreeding depression $\cdot$ Pedigree $\cdot$ Vulpes lagopus

\section{Introduction}

Mating behaviour is under strong selection pressure because of direct consequences for both individual life-history and has population-level demography. Based on the assumption that mating between close relatives is costly due to inbreeding depression, the inbreeding avoidance hypothesis proposes that by means of natural selection, active or passive mechanisms to avoid breeding with close relatives will evolve (Szulkin et al. 2013). According to Pusey and Wolf (1996), the presence of inbreeding depression is per se a strong enough force for evolution of inbreeding avoidance mechanisms. Such mechanisms may be physiological

Electronic supplementary material The online version of this article (https://doi.org/10.1007/s00300-018-2258-9) contains supplementary material, which is available to authorized users.

Karin Norén

karin.noren@zoologi.su.se

1 Department of Zoology, Stockholm University, 10691 Stockholm, Sweden through delayed maturation or reproductive suppression in the presence of relatives, or behavioural like mate choice, kin recognition or natal dispersal (e.g. Pusey and Wolf 1996; Heinsohn et al. 1998; Riehl 2013).

Discrimination of relatives most commonly concern firstorder relatives from the same natal group (Hoogland 1992; Geffen et al. 2011) and a possible consequence of not finding a suitable mate may be that adult individuals remain in their natal territory (Jennions and Macdonald 1994). Furthermore, existing social structures may further limit the availability of potential partners in a small population (Pusey and Wolf 1996). For instance, in species with long-term pair bonds, random mating can be prevented by existence of already established pair bonds. Furthermore, high levels of inbreeding can influence the duration of social structures such as pair bonds (Milleret et al. 2017).

Exclusion of relatives will inevitably decrease the number of potential mates, especially in a population of limited size (Johnstone et al. 1996). Mating patterns will thus be influenced by the costs related to both inbreeding itself as well as the costs of inbreeding avoidance strategies (i.e. lost 
chances of reproduction; Pusey and Wolf 1996; Jamieson et al. 2009). There are subsequently records of populations with high levels of inbreeding not showing any evidence for inbreeding avoidance strategies (Keller and Arcese 1998; Szulkin et al. 2009; Geffen et al. 2011; Olson et al. 2011).

Populations under detailed long-term monitoring are good model systems for addressing perspectives of inbreeding avoidance (e.g. Milleret et al. 2017). The Scandinavian Arctic fox (Vulpes lagopus) was an abundant tundra species until the late 19th century when fur harvesting almost drove the population to extinction (Angerbjörn et al. 2013). Despite protection under Swedish law since 1928, the population continued to decline because of ecological changes in the tundra ecosystem (Angerbjörn et al. 2013). Due to periods of irregular prey (Norwegian lemmings, Lemmus lemmus and voles, Myodes spp.) cycles in the 1980s and 1990s, the Arctic fox was exposed to food scarcity with reduced juvenile survival and reproduction as consequences. Furthermore, the expansion and establishment of red foxes (Vulpes vulpes) on the tundra starting during the late 19th century impacts negatively on the Arctic fox through competition and predation. The Arctic fox is well known for its extensive migration capacity (Wrigley and Hatch 1976), but despite this, the Scandinavian Arctic fox occurs in four more or less isolated subpopulations (Dalén et al. 2006). The southernmost Swedish subpopulation (Helags; Fig. 1a) was on the verge of extinction during the 1980s and 1990s, but increased fourfold in response to conservation actions (i.e. red fox control and supplementary feeding) between 2000 and 2010 (Fig. 1b; Angerbjörn et al. 2013). A recently published pedigree analysis revealed that the population is composed of five contributing founders, of which the historical level of inbreeding is unknown, and displays a minimum

(a)

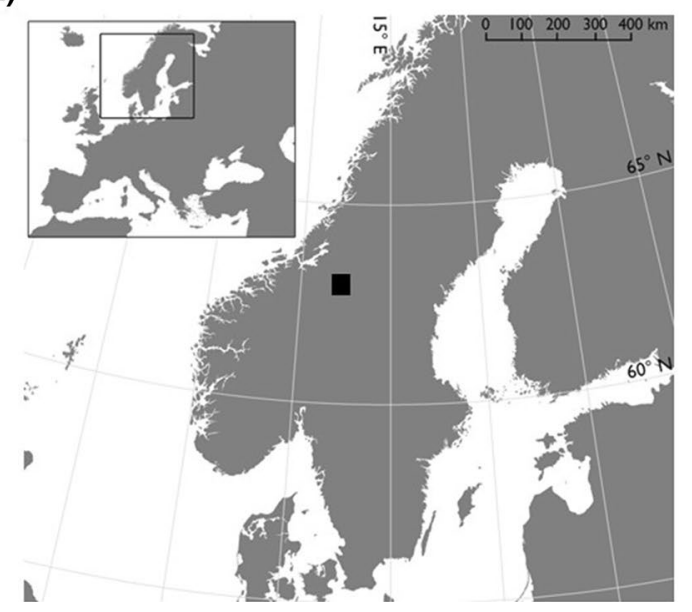

Fig. 1 a Map showing localization of the study population (black square), and b number of Arctic fox litters (2000-2009, grey bars) in a Swedish Arctic fox population with arrows indicating timing of inbreeding level corresponding to half-sibling matings (average inbreeding coefficient, $f=0.125$; Norén et al. 2016). Furthermore, the same study documented a pronounced cost of inbreeding depression by means of a significant reduction in first-year survival and reproductive success in inbred foxes (Norén et al. 2016).

The Arctic fox has a flexible mating system (Cameron et al. 2011; Norén et al. 2012; Elmhagen et al. 2014). The monogamous pair is the most common social unit, but larger groups consisting of up to six adults in the same den have been recorded (Norén et al. 2012). Based on visual observations of ear-tagged individuals, established pair bonds are only broken through mortality (Angerbjörn unpublished data). In complex social groups, additional, non-reproducing adults are usually first-order relatives (i.e. yearling offspring) to the breeding pair (Norén et al. 2012). Both ecological and population-related factors have an impact on how social and mating systems form (Cameron et al. 2011; Norén et al. 2012; Elmhagen et al. 2014). It is thus possible that high kin encounter rate and inbreeding levels will influence mate choice (Geffen et al. 2011).

However, little knowledge is available about how pairs form, and how potential inbreeding as well as availability of potential partners influence mating patterns. A previous study by Geffen et al. (2011) documented high kin encounter rates in the population, but low evidence for inbreeding avoidance. From a conservation perspective, understanding how inbreeding develops over time in this isolated population is of central concern to discuss and prioritize future actions.

This study focuses on mating patterns and occurrence of inbreeding avoidance in an inbred Arctic fox population. More specifically, we examine (1) if close relatives are (b)

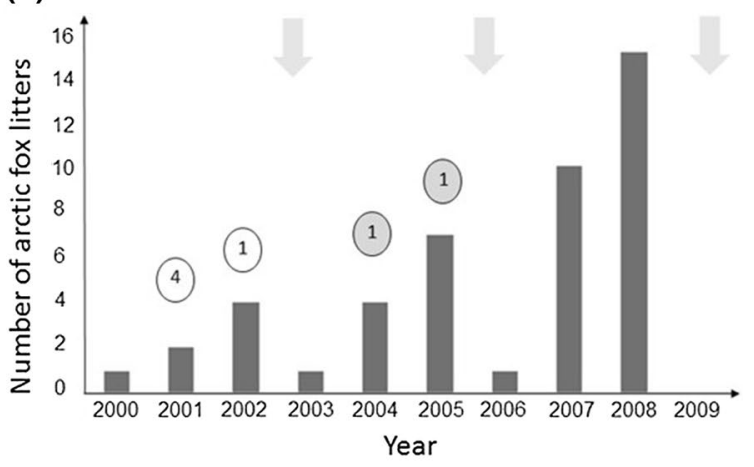

lemming crashes and circles showing the number of founders. Grey circles indicate founders without documented genetic contribution at the end of the study period 
discriminated as mates, (2) if the development of population inbreeding levels correspond to patterns of random mating, and (3) if there is a relationship between mating patterns and social group composition. Under a scenario without mate choice and inbreeding avoidance, we expect the population level of inbreeding to develop at the same rate as random mating with no discrimination of relatives or established pair bonds. Alternatively, if inbreeding is avoided, we expect the inbreeding level to increase at a slower rate than random mating, discrimination of close relatives and established pairs as mates and an increase in social group size (i.e. as a consequence of fewer available mates).

\section{Methods}

\section{Study population and background data}

Our study was conducted in the southernmost Swedish subpopulation $\left(62^{\circ} \mathrm{N}, 12^{\circ} \mathrm{E}\right.$, covering a total area of $\left.3400 \mathrm{~km}^{2}\right)$ in Helagsfjällen, Jämtland county between 2000 and 2008 (Fig. 1). Prior to the population bottleneck, the Arctic fox was abundant in the area, but in the 1980s and 1990s, the population was close to extinction (Angerbjörn et al. 2013). In response to intensive management actions in combination with natural re-appearance of lemming and vole cycles, the population increased fourfold over the study period (Angerbjörn et al. 2013, Fig. 1b).

Since year 2000, the population is under yearly monitoring. During July and August, all known dens $(n=68)$ were visited to document reproduction. When reproduction was confirmed, adults (if previously ear-tagged) were visually identified and pups as well as untagged adults were ear-tagged and ear tissue was collected for genetic analysis (Norén et al. 2016). Based on a total of 63 individuals ( $n$ males $=29, n$ females $=34$ ) visually and/or genetically verified to survive their first year (Norén et al. 2016), we used a two-step procedure to determine matings. We first conducted genetic parentage testing between adults visually observed with pups at a den site. When pups and adults matched in allelic composition, no further analysis was undertaken. If there was a mismatch between pups and adults, or adults were not sampled, we conducted a parentage analysis between pups and all adults, present in the population at the time (Norén et al. 2016). To assess individualand population-level inbreeding coefficients $\left(f_{\text {obs }}\right)$, as well as relationship between all mated pairs, we used a genetically verified pedigree including 205 individuals $(n$ males $=106$, $n$ females $=99$; Norén et al. 2016) in combination with maximum likelihood relatedness calculations implemented in the software ML Relate (Kalinowski et al. 2006) and validated in the software COLONY (Jones and Wang 2010). This was based on microsatellite data for eleven loci with a combined probability of identity (PI) $<10^{-7}$ (detailed procedure described in Norén et al. 2012, 2016). All handling of animals followed the ASM guidelines and were approved by a Swedish ethical permit (A131-07).

During the yearly inventories, we also collected data on social group size at reproductive dens. The size and composition of social groups were determined using a combination of visual observations and genetic analysis (Norén et al. 2012; Elmhagen et al. 2014). A simple social group is defined as a male and a female with pups, whereas a complex social group consisted of more than two adults (Norén et al. 2012). Data on social group composition recorded between 2000 and 2005 have previously been published (Norén et al. 2012; Elmhagen et al. 2014), while data from 2007 to 2008 are previously unpublished. To test if there was a relationship between inbreeding and occurrence of complex social groups, we compared the proportion of matings between related individuals to the proportion of complex groups using a linear regression test in $\mathrm{R}$.

\section{Simulations of inbreeding development}

Based on the breeding adults documented as present each year, all possible pair combinations were constructed and the inbreeding coefficient $\left(f_{\text {sim }}\right)$ of their potential offspring was calculated. Among these values, 10 matings were randomly selected and this procedure was repeated 10,000 times. Thereafter, the average yearly inbreeding coefficient $\left(f_{\text {sim }}\right)$ was calculated.

First, we constructed pairs based on a yearly cohort during 2000-2008, without any exclusion (i.e. random mating, assuming no discrimination of close relatives or established pairs). Second, we repeated the procedure above, but assuming three scenarios: (1) discrimination of first-order relatives from the same natal family, (2) exclusion of individuals already present in an established pair bond (based on the lack of observed divorces in established pairs), and (3) a combination of scenarios (1) and (2). Based on this, the simulated, expected development of inbreeding $\left(f_{\text {sim }}\right)$ under random mating and scenario 1-3 were compared to the observed inbreeding $\left(f_{o b s}\right)$ development during 2004-2008 using linear regression tests in $\mathrm{R}$.

\section{Results}

During the course of this study, the observed inbreeding level increased from $f_{o b s}=0$ to $f_{\text {obs }}=0.125$ which corresponds to an overall level of half-sibling matings. Based on 35 matings over the study period, we recorded 16 matings between unrelated mates $\left(f_{\text {obs }}=0\right), 17$ matings between second-order relatives $\left(f_{o b s}=0.0625-0.1865\right)$ and two matings between first-order relatives $\left(f_{o b s}=0.25\right)$ (Fig. 2a). The 
latter mating form was two pairs of full-siblings originating from different natal litters (i.e. born in different years, but from the same parental pair) and occurred during the final two years of the study. During the study period, matings between second-order relatives in the population increased considerably (Fig. 2b).

The simulations of inbreeding development show fast, expected increases in population inbreeding under random mating as well as under a scenario of excluding only individuals in previously established pairs (Fig. 3, for detailed data, see Electronic Supplementary Material 1). We found no significant relationship between the observed inbreeding development and simulated random mating (linear regression, $r^{2}=0.354, P=0.20$ ). We found a highly significant relationship with our observed data and exclusion of natal family (scenario 1 ; linear regression, $r^{2}=0.98, P<0.001$ ) as well as the combination between exclusion of natal family and established pairs (scenario 3; linear regression, $\left.r^{2}=0.964, P<0.001\right)$. However, the exclusion of established pairs was not related to the observed data (scenario 2 ; linear regression, $r^{2}=0.159, P=0.327$ ). The $95 \%$ confidence intervals of simulated mating scenarios are shown in Electronic Supplementary Material 1.

During the study period, we recorded 29 simple social groups (i.e. two adults), and 12 others comprised of more than adults. We investigated the pattern of group size over time and found an increase in the proportion of social groups during peak years (Fig. 2c). There was, however, no relationship between the proportion of inbred matings $(f>0)$ to the proportion of complex social groups (linear regression, $\left.r^{2}=-0.018, P=0.385\right)$.

\section{Discussion}

The goal of this study was to investigate mating patterns in an inbred Arctic fox population with specific emphasis on evaluating if inbreeding avoidance can slow down the development of population inbreeding levels. A previous study by Geffen et al. (2011) found no evidence for inbreeding avoidance in this population and proposed that mating occurred completely random. In contrast, we found a complete lack of recorded matings between first-order relatives from the same natal group which suggests that there is a strong discrimination of close relatives as mating partners (Fig. 2a, b). Matings between second-order relatives, however, seemed to occur to the same extent as matings between unrelated individuals (Fig. 2a). This may however be a consequence of low (and with time decreasing) access to unrelated partners; at the end of the study period, only one mating between unrelated individuals was documented.

Discrimination of natal family also has a clear impact on the population development of inbreeding level. We found that the observed level of inbreeding was considerably lower than what would be expected from random mating. Our empirical data showed a similar development of inbreeding levels as the simulated scenario of discriminating natal family as pair mates. A previous study documented a tenfold increase in population inbreeding levels over the study period (Norén et al. 2016). The process causing this rise seems to be mainly matings between second-order relatives. As expected, we can also see that the number of inbred matings increase strongly during the study period (Fig. 2b). Since the study was conducted in a growing population (Fig. 1b), there will be an increase in the proportion of relatives which, in turn, will increase the kin encounter rate and subsequent inbreeding.

The mechanism underlying kin recognition is discussed in several previous papers. Since there is a low occurrence of full-sibling matings, the most likely mechanism underlying kin recognition of natal family would be early development imprinting from the natal family (Mateo 2003). There seems to be no discrimination of matings with second-order relatives (Fig. 2a, b) and the increase in inbreeding seems to be caused by this type of matings. In other inbred populations, discrimination of first-order relatives is the most common form of inbreeding avoidance (Hoogland 1992; McNutt 1996; Randall et al. 2007; Sparkman et al. 2012). However, whether or not discrimination of more distant relatives occurs is less well established (Pusey and Wolf 1996), and deserves future research attention. It is, however, possible that avoidance of more distant relatives would, in terms of lost chances of reproduction, be too costly in a population originating from such a limited number of founders.

Occurrence of inbreeding depression is proposed to be a sufficient selection pressure for the evolution of inbreeding avoidance strategies (Pusey and Wolf 1996). Our data partly support this statement. Norén et al. (2016) demonstrated that inbreeding negatively impacts fundamental fitness traits (i.e. first-year survival and reproduction). However, inbreeding between second-order relatives occur frequently and appears to be the main driver underlying both the increase in inbreeding levels as well as inbreeding depression. Since the population, in response to conservation actions (i.e. supplementary feeding and red fox control) as well as the natural re-appearance of more regular prey cycles (Angerbjörn et al. 2013), simultaneously underwent a strong population increase, inbreeding depression itself is not a sufficient factor to prevent population growth. It could however still impede the rate of increase and hence population recovery. Furthermore, strict inbreeding avoidance strategies may incur higher costs in cyclic populations. Since reproduction occurs exclusively during increase and peak phases (Tannerfeldt and Angerbjörn 1998; Meijer et al. 2013), strict discrimination is associated with a risk of missed opportunities for reproducing and an individual fitness equal to zero. Therefore, the 
Fig. 2 a Total number of matings between unrelated, secondorder relatives and first-order relatives, $\mathbf{b}$ number of matings between unrelated, second-order relatives and first-order relatives (2001-2008), and c number of simple and complex social groups (2001-2008) in a Swedish Arctic fox population. Grey arrows show timing of crashes in the lemming cycle
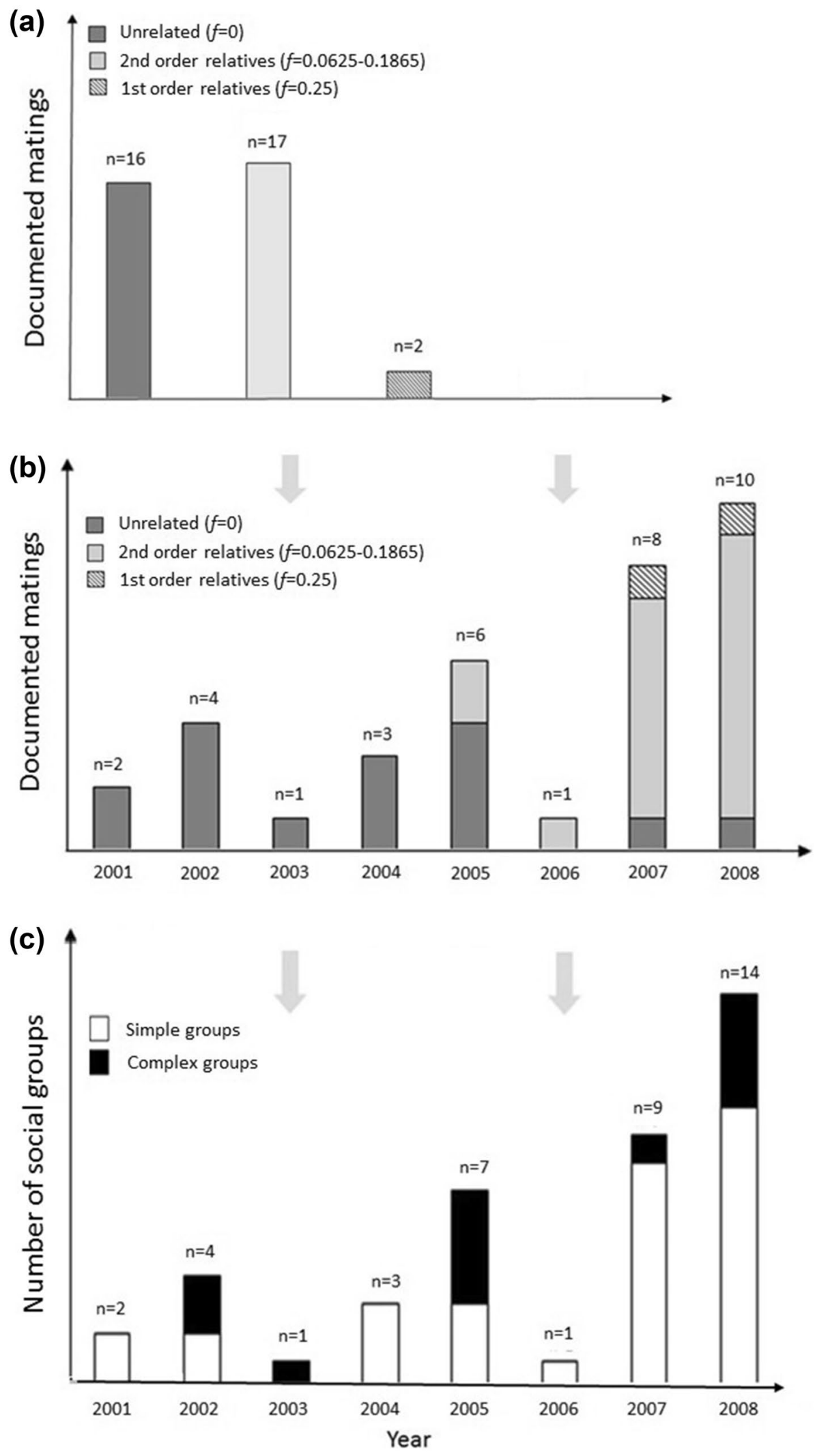


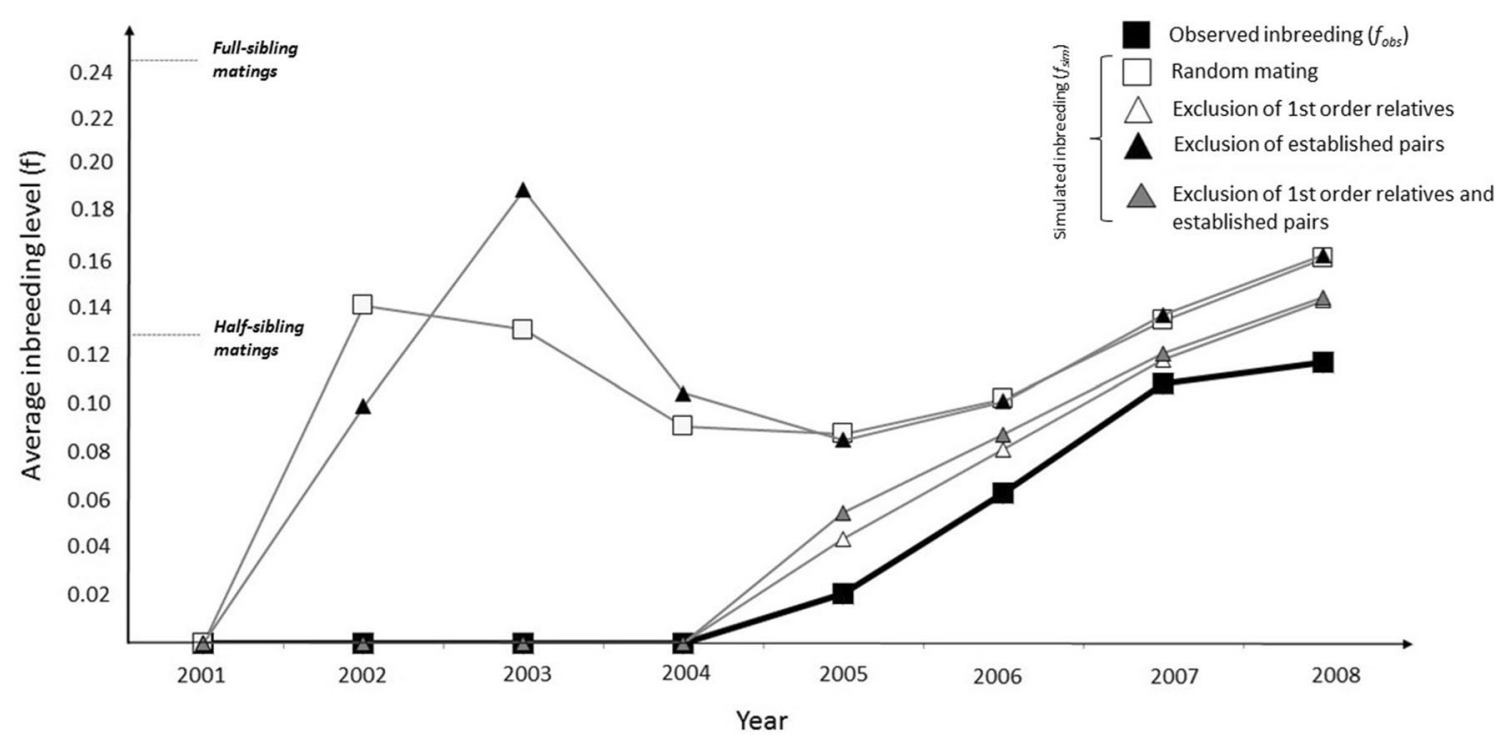

Fig. 3 Observed ( $f_{\text {obs }}$ black line) and simulated ( $f_{\text {sim }}$ grey lines) inbreeding development (2001-2008) for different mating scenarios in a Swedish Arctic fox population. Dashed lines represent the expected inbreeding coefficient $\left(f_{\text {sim }}\right)$ for full- and half-sibling matings

benefit of breeding with a second-order relative may exceed the potential risk for inbreeding depression (Pusey and Wolf 1996). Another aspect that is necessary to address is that we have assumed the population founders are completely outbred $(f=0)$. A possible consequence of this is that the population inbreeding level may be underestimated and the individual inbreeding coefficients may actually be higher due to the historical level of inbreeding in the founders. Our genetic markers do not contain sufficient resolution to identify the relationship between the original founders and their historical inbreeding levels, but future efforts using whole-genome sequencing will provide detailed answers regarding this.

We also examined if inbreeding avoidance could influence the size of social groups by an increase in the number of groups containing additional, non-reproducing individuals. We found no direct relationship between the occurrence of inbred matings and the size of social groups (Fig. 2b, c). However, investigating the proportion of complex social groups (Fig. 2c) revealed a tendency towards an increase during lemming peak years (2005 and 2008). During a year of increase in the lemming cycle (2004 and 2007), larger litters are born and survival among Arctic fox pups is higher (Meijer et al. 2013). Due to a higher proportion of survival in each litter, there will be a higher proportion of surviving siblings leading to an increase in both the number of individuals, and possibly also the average level of relatedness in the population. Therefore, there may be a higher occurrence of related yearlings remaining in their natal territory, possibly due to difficulties in finding a (sufficiently) unrelated partner. Hence, the temporal changes in social structure may be a consequence of inbreeding avoidance that occurs with a one-year time lag in response to increased number of relatives. Connected to this, Milleret et al. (2017) recorded that inbreeding coefficient contributed to a decrease in pair duration (i.e. lowered pair bond stability) in the Scandinavian grey wolf (Canis lupus). Hence, a higher inbreeding coefficient $(f)$ can contribute to a higher probability of pair dissolution and hence changes in social structures.

In conclusion, mating patterns are the outcome of a complex interplay between multiple factors. This study demonstrates evidence for behavioural, pre-copulation inbreeding avoidance and that discrimination of natal family slows down the development of population inbreeding in an isolated Arctic fox population. Even though there seems to be strong selection for inbreeding avoidance, we conclude that discrimination of natal family is not sufficient for preventing inbreeding levels from increasing rapidly in a population originating from a limited number of founders, which is particularly troublesome in a population with documented inbreeding depression (Norén et al. 2016). From a conservation perspective, the results from this study clearly illustrates the importance of bringing new genetic material into the population, either through active translocation actions or by natural immigration through management actions in stepping stone sites to mediate connectivity between core populations.

Acknowledgements We are grateful to rangers and volunteers carrying out an immense amount of fieldwork, to R. Erlandsson for supplying maps and to Tom Smith as well as one anonymous referee for useful review comments on the manuscript. This study was financed by EU LIFE to SEFALO+, the Swedish Nature Protection Agency, WWF, Fjällräven AB, the Royal Physiographic Society of Lund, the Swedish Research Council FORMAS (\#2010-263, \#2011-1015 and 
\#2015-1526 to KN) and EU/Interreg Sweden Norway to Felles Fjellrev II (\#20200939).

Open Access This article is distributed under the terms of the Creative Commons Attribution 4.0 International License (http://creativeco mmons.org/licenses/by/4.0/), which permits unrestricted use, distribution, and reproduction in any medium, provided you give appropriate credit to the original author(s) and the source, provide a link to the Creative Commons license, and indicate if changes were made.

\section{References}

Angerbjörn A, Eide NE, Dalén L, Elmhagen B, Hellström P, Ims RA, Killengreen S, Landa A, Meijer T, Mela M, Niemimaa J, Norén K, Tannerfeldt M, Yocooz NG, Henttonen H (2013) Carnivore conservation in practice: replicated management actions on a large spatial scale. J Appl Ecol 50:59-67. https://doi. org/10.1111/1365-2664.12033

Cameron C, Berteaux D, Dufresne F (2011) Spatial variation in food availability predicts extrapair paternity in the Arctic fox. Behav Ecol 22:1364-1373. https://doi.org/10.1093/beheco/arr158

Dalén L, Kvaloy K, Linnell JDC, Elmhagen B, Strand O, Tannerfeldt M, Strand O, Henttonen H, Fuglei E, Landa A, Angerbjörn A (2006) Population structure in a critically endangered Arctic fox population: does genetics matter? Mol Ecol 15:2809-2819. https ://doi.org/10.1111/j.1365-294X.2006.02983.x

Elmhagen B, Hersteinsson P, Norén K, Unnsteinsdottir ER, Angerbjörn A (2014) From breeding pairs to fox towns: the social organisation of Arctic fox populations with stable and fluctuating availability of food. Polar Biol 37:111-122. https://doi.org/10.1007/s0030 0-013-1416-3

Geffen E, Kam M, Hefner R, Hersteinsson P, Angerbjörn A, Dalen L, Fuglei E, Norén K, Adams JR, Vucetich J, Meier TJ, Mech LD, Vonholdt BM, Stahler DR, Wayne RK (2011) Kin encounter rate and inbreeding avoidance in canids. Mol Ecol 20:5348-5358. https://doi.org/10.1111/j.1365-294X.2011.05358.x

Heinsohn RG, Cockbu A, Cunningham RB (1998) Foraging, delayed maturation, and advantages of cooperative breeding in whitewinged choughs, Corcorax melanorhamphos. Ethology 77:177186. https://doi.org/10.1111/j.1439-0310.1988.tb00202.x

Hoogland JL (1992) Levels of inbreeding among prairie dogs. Am Nat 139:591-602. https://doi.org/10.1086/285345

Jamieson IG, Taylor SS, Tracy LN, Kokko H, Armstrong DP (2009) Why some species of birds do not avoid inbreeding: insights from New Zealand robins and saddlebacks. Behav Ecol 20:575-584. https://doi.org/10.1093/beheco/arp034

Jennions MD, Macdonald DW (1994) Cooperative breeding in mammals. Trends Ecol Evol 9:89-93. https://doi.org/10.1007/3-54028277-7_10

Johnstone RA, Reynolds JD, Deutsch JC (1996) Mutual mate choice and sex differences in choosiness. Evolution 50:1382-1391. https ://doi.org/10.2307/2410876

Jones OR, Wang J (2010) COLONY: a program for parentage and sibship inference from multilocus genotype data. Mol Ecol Res 10:551-555. https://doi.org/10.1111/j.1755-0998.2009.02787.x
Kalinowski ST, Wagner AP, Taper ML (2006) ML-Relate: a computer program for maximum likelihood estimation of relatedness and relationship. Mol Ecol Notes 6:576-579. https://doi.org/10.111 1/j.1471-8286.2006.01256.x

Keller LF, Arcese P (1998) No evidence for inbreeding avoidance in a natural population of song sparrows. Am Nat 152:380-392. https ://doi.org/10.1086/286176

Mateo JM (2003) Kin recognition in ground squirrels and other rodents. J Mammal 84:1163-1181. https://doi.org/10.1644/BLe-011

McNutt JW (1996) Sex-biased dispersal in African wild dogs, Lycaon pictus. Anim Behav 52:1067-1077. https://doi.org/10.1006/ anbe.1996.0254

Meijer T, Elmhagen B, Eide NE, Angerbjörn A (2013) Life history traits in a cyclic ecosystem- a field experiment on the Arctic fox. Oecol 173:439-447. https://doi.org/10.1007/s00442-013-2641-8

Milleret C, Wabakken P, Liberg O, Åkesson M, Flagstad Ø, Andreassen HP, Sand H (2017) Let's stay together? Intrinsic and extrinsic factors involved in pair bond dissolution in a recolonizing wolf population. J Anim Ecol 86:43-54. https://doi. org/10.1111/1365-2656.12587

Norén K, Hersteinsson P, Samelius G, Eide NE, Fuglei E, Elmhagen B, Dalén L, Meijer T, Angerbjörn A (2012) From monogamy to complexity: Arctic fox social organization in contrasting ecosystems. Can J Zool 90:1102-1116. https://doi.org/10.1139/z2012-077

Norén K, Godoy E, Dalén L, Meijer T, Angerbjörn A (2016) Inbreeding depression in a critically endangered carnivore. Mol Ecol 25:3309-3318. https://doi.org/10.1111/mec.13674

Olson LE, Blumstein DT, Pollinger JR, Wayne RK (2011) No evidence of inbreeding avoidance despite demonstrated survival costs in a polygynous rodent. Mol Ecol 21:562-571. https://doi. org/10.1111/j.1365-294X.2011.05389.x

Pusey A, Wolf M (1996) Inbreeding avoidance in animals. Trends Ecol Evol 11:201-206. https://doi.org/10.1016/0169-5347(96)10028-8

Randall DA, Pollinger JP, Wayne RK, Tallents LA, Johnson PJ, Macdonald DW (2007) Inbreeding is reduced by female-biased dispersal and mating behaviour in Ethiopian wolves. Behav Ecol 18:579-589. https://doi.org/10.1093/beheco/arm010

Riehl C (2013) Evolutionary routes to non-kin cooperative breeding in birds. Proc Royal Soc B 280:20132245. https://doi.org/10.1098/ rspb.2013.2245

Sparkman AM, Adams JR, Steury TD, Waits LP, Murray DL (2012) Pack social dynamics and inbreeding avoidance in the cooperatively breeding red wolf. Behav Ecol 23:1186-1194. https://doi. org/10.1093/beheco/ars099

Szulkin M, Zelakowski P, Nicholson G, Sheldon BC (2009) Inbreeding avoidance under different null models of random mating in the great tit. J Anim Ecol 78:778-788. https://doi.org/10.111 1/j.1365-2656.2009.01544.x

Szulkin M, Stopher KV, Pemberton JM, Reid JM (2013) Inbreeding avoidance, tolerance, or preference in animals? Trends Ecol Evol 28:205-211. https://doi.org/10.1016/j.tree.2012.10.016

Tannerfeldt M, Angerbjörn A (1998) Fluctuating resources and the evolution of litter size in the Arctic fox. Oikos 83:545-559. https ://doi.org/10.2307/3546681

Wrigley RE, Hatch DRM (1976) Arctic fox migrations in Manitoba. Arctic 29(147):158. https://doi.org/10.14430/arctic2798 